\title{
REDACTIONEEL
}

\section{Een nieuwe impuls aan het methodendebat ${ }^{*}$}

\author{
Sanne Taekema \& Bart van Klink
}

\section{Methoden van rechtswetenschap: een voortdurend debat}

Voor Nederlandse juristen zal de combinatie 'recht en methode' associaties oproepen met de bekende discussie over de aard van de rechtswetenschap. Een van de centrale kenmerken van wetenschap is dat deze beoefend wordt met een beproefde werkwijze die liefst als zodanig wordt erkend door vakgenoten. Overigens, als een methode niet breed geaccepteerd wordt, is deze vaak voorwerp van intens debat, zozeer dat er in verschillende disciplines van methodenstrijd wordt gesproken. ${ }^{1}$ Beide vormen van aandacht voor wetenschappelijke methoden ontbraken tot voor kort nagenoeg in het juridische debat: juristen zwegen meestal over hun methoden.

Dat veranderde met de bekende lezing van Carel Stolker uit 2003, 'Ja, geléérd zijn jullie wel', waarin hij de (mogelijke) kritiek van wetenschappers uit andere disciplines op de rechtswetenschap aangreep om juristen een spiegel voor te houden: hebben rechtswetenschappers wel navolgbare methoden en moeten wij niet veel meer aandacht hebben voor de kwaliteit van onze onderzoeksmethoden? De aanzet van Stolker heeft geleid tot een debat over de wetenschappelijke kwaliteit van de rechtsgeleerdheid dat nog steeds niet is uitgewoed. In eerste instantie speelde het debat zich voornamelijk af op de pagina's van het Nederlands Juristenblad, maar inmiddels heeft het ook geleid tot allerlei andere publicaties ${ }^{2}$ en tot grotere aandacht voor methodologie in de juridische opleiding, zowel op de universiteit als op het hbo. ${ }^{3}$ Wat opvalt aan de bijdragen aan het debat, is de pluraliteit aan opvattingen, niet alleen over de juiste kenschets van de rechtswetenschap en de geëigende methoden, maar ook over de vraag of aandacht voor methoden eigenlijk nodig is. Juist door deze metavraag naar het belang van methodologie wijkt het juridische debat af van andere wetenschappen, waar de noodzaak van een verantwoorde methodologie buiten kijf staat. Sommige juristen menen dat de methode van onderzoek impliciet kan blijven en dat de inhoudelijke kwaliteit van het verrichte onderzoek een betere maatstaf is voor goed onderzoek dan een

* Prof. Sanne Taekema is hoogleraar aan de Erasmus School of Law in Rotterdam. Prof. dr. Bart van Klink is hoogleraar Methoden en Technieken van Recht en Rechtswetenschap aan de Vrije Universiteit Amsterdam.

1 Een van de bekendste debatten is de strijd tussen Erklären en Verstehen in de sociale wetenschappen, zie ook hieronder in paragraaf 4.

2 Monografieën, zoals Smits 2009, proefschriften zoals Wendt 2008, themanummers zoals het NJB-themanummer 'De rechtswetenschap' uit 2004.

3 Met bijbehorende leerboeken zoals Sumner e.a. 2010, Kloosterhuis 2009, Van Schaaijk 2011. 
expliciete methodenparagraaf (Mackor 2007). Voor anderen is de vraag naar een rechtswetenschappelijke methode niet los te zien van methoden van rechtsvinding (Franken 2004). Aangezien die traditioneel wel in de belangstelling staan, is er dan eigenlijk geen behoefte aan meer, of beter verantwoorde, methodologie.

Ook binnen de groep juristen die aandacht voor methodologie bepleit is de variatie groot. Een belangrijke discussie betreft de formele kenmerken van wetenschappelijk onderzoek. Barendrecht en anderen (2004) pleitten voor een duidelijke probleemstelling en een expliciete methodologische verantwoording in juridische publicaties. ${ }^{4}$ Dat leidde tot een flink aantal publicaties over criteria voor goed rechtswetenschappelijk onderzoek (bijvoorbeeld Van Gestel \& Vranken 2007; Smith e.a. 2008). Een meer inhoudelijke discussie wordt gevoerd over de aard van de rechtswetenschap en de methoden die daarbij horen. Centraal daarin staat de normativiteit van de rechtswetenschap. Voor sommigen impliceert de normativiteit van praktisch juridisch redeneren dat ook rechtswetenschap in essentie normatief is (Smith e.a. 2008). Anderen benadrukken juist dat empirische kennis over het recht de kern van de rechtswetenschap uitmaakt (De Geest 2004). Een dergelijke karakterisering van de rechtswetenschap heeft ook consequenties voor de aard van de juridische methoden: een normatief georiënteerde rechtswetenschap vindt haar inspiratie bij de hermeneutische methoden van de geesteswetenschappen, een empirisch georiënteerde rechtswetenschap zoekt aansluiting bij de sociale wetenschappen (vergelijk Soeteman 2010). In dit tijdschrift is plaats voor het hele spectrum van methodologische opvattingen over rechtswetenschap.

\section{Nog een juridisch tijdschrift?}

Toen wij John Griffiths, emiritus hoogleraar Rechtssociologie uit Groningen, benaderden voor een bijdrage aan ons nieuwe tijdschrift, antwoordde hij ons dat hij zich afvroeg of er werkelijk behoefte is aan nóg een juridisch tijdschrift. Hij constateerde enerzijds een exponentiële groei aan tijdschriften op het terrein van het recht en anderzijds een afname van de kwaliteit van de hierin gepubliceerde artikelen. Bovendien, zo vroeg hij zich af, wie kan dat allemaal kan lezen? Dat zijn beide terechte vragen, die uiting geven aan een begrijpelijke zorg over de manier waarop het wetenschappelijk bedrijf in de huidige tijd is ingericht. In algemene zin geldt, wie wat wenst toe te voegen aan de bestaande werkelijkheid, moet rechtvaardigen waarom hij dat doet. De Duitse filosoof en theoloog Odo Marquard (2003, p. 154) stelt: 'stets müssen mehr Üblichkeiten aufrechterhalten werden als verändert, sonst ruiniert man unser Leben; und die (...) Beweislast hat stets der Veränderer.' Met de oprichting van dit tijdschrift willen wij geenszins het academische leven verstoren laat staan te gronde richten, maar juist de reflectie op gangbare praktijken in de rechtswetenschap bevorderen, zowel wat betreft het onderzoek als het onderwijs. Er hebben zich de afgelopen jaren verschillende

4 Of dit ook gebeurt is systematisch onderzocht door Tijssen ten aanzien van juridische dissertaties (2009). 
ontwikkelingen voorgedaan in de maatschappelijke en wetenschappelijke context waarbinnen de rechtswetenschap functioneert, die met elkaar hebben geleid tot een grotere aandacht voor methodologische kwesties. Ten eerste zien rechtswetenschappers zich steeds meer genoodzaakt, in de competitie om onderzoeksgelden, de methoden die zij hanteren te expliciteren en te rechtvaardigen tegenover wetenschappers uit andere disciplines, die niet altijd overtuigd zijn van de wetenschappelijke kwaliteit en relevantie van het rechtsgeleerde onderzoek. Onder juristen bestaat de indruk dat rechtswetenschappelijke onderzoeksvoorstellen verhoudingsgewijs minder vaak financiële middelen toegekend krijgen dan onderzoeksvoorstellen uit andere, en dan vooral de empirische disciplines. Volgens Ybo Buruma (2007, p. 1043) wordt aan rechtswetenschappelijk onderzoek minder geld uitgegeven dan aan ander onderzoek, 'omdat juristen er minder dan bijvoorbeeld cognitiepsychologen in slagen anderen te overtuigen van het belang en de kwaliteit van hun onderzoeksvoorstellen.' Ten tweede leeft er bij rechtswetenschappers in toenemende mate de wens om verder te gaan of iets anders te doen dan klassiek positiefrechtelijk onderzoek. Steeds vaker maken zij in hun onderzoek gebruik van inzichten uit hulpdisciplines, zoals de economie, sociologie en psychologie om bepaalde aspecten van het recht te belichten die bij het traditionele onderzoek geheel of grotendeels buiten beeld blijven. Zo heeft Suzan van der $\mathrm{Aa}$ - een rechtswetenschapper van opleiding - een proefschrift geschreven over het verschijnsel stalking in Nederland dat voornamelijk sociaalwetenschappelijk van aard is (Van der Aa 2010). Hoewel een multi- of interdisciplinaire aanpak interessante mogelijkheden biedt voor vernieuwend onderzoek, stelt het hoge eisen aan onderzoekers omdat zij niet alleen goed thuis moeten zijn in de methodologie van rechtswetenschappelijk onderzoek maar ook in die van de hulpdiscipline. Meer principieel doet zich vanuit de kenleer de vraag voor of er tussen verschillende disciplines wel een zinvolle uitwisseling van inzichten en methoden mogelijk is en of begrippen van de ene discipline zomaar naar de andere discipline overgezet kunnen worden. ${ }^{5}$ Ten derde wordt er in juridische opleidingen steeds meer aandacht besteed aan het trainen van voor een jurist onmisbare vaardigheden op het gebied van taalbeheersing, informatieverwerving en -verwerking, argumentatie, spreken en schrijven en het doen van rechtswetenschappelijk onderzoek, omdat niet langer als vanzelfsprekend kan of mag worden aangenomen dat studenten deze vaardigheden bezitten of uit zichzelf verwerven. Daarbij is ook de vraag in hoeverre het vaardighedenonderwijs dat op universitaire rechtenopleidingen wordt aangeboden, zich nog onderscheidt of zou moeten onderscheiden van dat in het hoger beroepsonderwijs. Wat zijn nu specifiek academische juridische vaardigheden en hoe moeten deze getraind worden? Ten slotte dwingt de toenemende internationalisering rechtswetenschappers in Nederland ertoe na te denken over de vraag of de manier waarop we hier gewend zijn onderzoek te doen en onderwijs te geven overeenkomt met elders gangbare praktijken en de daar geldende maatstaven. Als onderzoekers internationale erkenning willen krij-

5 Voor een uitvoerige bespreking van mogelijkheden en beperkingen van multi- en interdisciplinair onderzoek in de rechtswetenschap, zie Taekema \& Van Klink 2011. 
gen voor hun onderzoek zullen zij aansluiting moeten zoeken bij internationale ontwikkelingen of in elk geval positie moeten kiezen in internationale discussies.

\section{Doelstelling en inhoud}

Het tijdschrift Recht en Methode in onderzoek en onderwijs (ReM) beoogt een platform te bieden voor rechtswetenschappers die willen discussiëren over deze ontwikkelingen en hun betekenis voor de praktijk van het juridisch onderzoek en onderwijs, op een uitvoeriger en systematischer wijze dan in andere juridische tijdschriften mogelijk is. Het methodendebat in de rechtswetenschap staat - zeker in vergelijking met de sociale wetenschappen, maar bijvoorbeeld ook met de geschiedwetenschap, de linguïstiek en de filosofie - nog in de kinderschoenen en met dit tijdschrift zouden we dat graag een aantal stappen verder willen brengen.

Het is niet de bedoeling om het tijdschrift te vullen met enkel theoretische bijdragen over de aard van juridische methoden. Met de groeiende aandacht voor methoden komt het regelmatig voor dat juristen innovatieve methoden gebruiken, terwijl de keuze voor die methoden en de verantwoording ervan slechts zeer beperkt aandacht kunnen krijgen in het kader van een inhoudelijk artikel. Het tijdschrift ReM is ook een plek om nieuwe methoden die in de praktijk van het wetenschappelijk werk ontwikkeld worden voor het voetlicht te brengen. Daarbij beperken wij de aandacht niet tot rechtswetenschappers, maar is er ook ruimte voor onderzoekers uit andere disciplines die hun methoden met het recht in verband brengen.

Naast artikelen over rechtswetenschappelijke methoden bieden wij ook ruimte voor reflectie op methoden verbonden met de rechtspraktijk, zoals methoden van wetgeving, rechtsvinding en juridische argumentatie. Zowel ten aanzien van rechtspraktijk als rechtswetenschap zijn wij ook geïnteresseerd in artikelen die zich verdiepen in de eigen praktijk van de jurist of wetenschapper: op welke methodologische problemen stuit men en welke oplossingen zijn daarvoor mogelijk?

Ook reflectie op het juridisch onderwijs hoort daarbij. Interessante vragen in dit verband zijn: welke methodologische handvatten bieden wij aankomende juristen? Op welke manier kan methodenonderwijs het beste worden vormgegeven en hoe kan daarbij worden ingespeeld op de specifieke doelgroep van hbo- of universitaire studenten?

Welke onderwerpen zouden in het tijdschrift aan de orde moeten of mogen komen? Zonder het debat daartoe te willen beperken, noemen wij hieronder drie actuele thema's die naar onze mening tot nader onderzoek aanleiding geven. 


\section{(i) De verhouding tussen rechtswetenschap en rechtspraktijk}

De rechtswetenschap wordt vaak gezien als een maatschappijwetenschap, die tot taak heeft te onderzoeken hoe de maatschappij kan worden verbeterd met behulp van het recht. Zodra er zich een maatschappelijk probleem voordoet, is al snel de vraag: hoe lossen we het juridisch op? Vanuit de rechtspraktijk wordt rechtswetenschappers geregeld advies gevraagd, bijvoorbeeld bij de voorbereiding van een rechtszaak of een wetsvoorstel. Deze maatschappelijke 'dienstverlening' is een belangrijk onderdeel van de rechtswetenschap en zal altijd een kerntaak blijven. Traditiegetrouw rekenen rechtswetenschappers het tot hun taak de rechtspraktijk te informeren over de stand van zaken in het recht en te reageren op wetsvoorstellen en rechterlijke uitspraken. Volgens sommige rechtswetenschappers heeft deze praktische oriëntatie de rechtsgeleerdheid gehinderd in haar ontwikkeling tot een 'echte' wetenschap. Het is voor de ontwikkeling van de rechtswetenschap van groot belang dat zij een zelfstandige positie inneemt ten opzichte van de rechtspraktijk en zich ook met vraagstukken inlaat die geen of geen direct maatschappelijk belang lijken te dienen en die verder gaan dan één enkele rechtszaak of een specifiek wetsvoorstel. Zoals de commissie-Smits ${ }^{6}$ aangeeft, verschijnen er veel vakpublicaties die niet meer doen dan de bestaande kennis over een bepaald rechtsgebied weergeven of concrete suggesties doen om het bestaande recht te verbeteren. Handig voor de praktijk, maar wetenschappelijk gezien niet altijd even interessant. De vraag is hoe de verhouding tussen toegepast en 'zuiver' rechtswetenschappelijk onderzoek zou moeten zijn en of er hiertussen altijd een tegenstelling bestaat. Hoe kan de wetenschappelijkheid van toegepast onderzoek worden gewaarborgd? Van oudsher worden onderzoeksvragen in de rechtswetenschap meestal vanuit het perspectief van de rechter gesteld - hoe moet hij of zij in concrete gevallen beslissen? De vraag is of er niet ook vanuit andere perspectieven, bijvoorbeeld die van de wetgever of de advocaat, gekeken zou moeten worden. Omgekeerd is de vraag in hoeverre de rechtspraktijk zich meer moet openstellen voor inzichten uit de wetenschap, zoals onder meer de rechtspsycholoog Peter van Koppen (2011) bepleit. Of zouden praktijkjuristen zich juist meer autonoom moeten opstellen, ook tegenover kennisaanspraken van de wetenschap? ${ }^{7}$

\section{(ii) Mogelijkheden en beperkingen van multi- en interdisciplinair onderzoek}

Zoals bekend verrichten rechtswetenschappers in toenemende mate onderzoek geheel of gedeeltelijk buiten het gebied waarvoor zij zijn opgeleid. Hierbij doen zich problemen van praktische aard voor, zoals: hoe moet je als jurist (soms conflicterende) kennisaanspraken van andere disciplines beoordelen of hoe raak je snel thuis in een andere discipline? Maar bij multi- en interdisciplinair onderzoek doen zich ook meer fundamentele vraagstukken van wetenschapstheoretische aard voor. Zo is bijvoorbeeld de vraag hoe ware en onware beweringen van elkaar kunnen worden onderscheiden. Naar algemeen wordt aangenomen, is het doel

6 Commissie Prestatie-indicatoren en ranking, ingesteld door het Disciplineoverlegorgaan Rechtsgeleerdheid van de VSNU, Naar prestatie-indicatoren voor rechtswetenschappelijk onderzoek, maart 2007.

7 Zie over dit debat de oraties van Mackor 2011, Taekema 2010 en Van Klink 2010. 
van wetenschap het vergaren van kennis. Maar wat als ware kennis geldt, en hoe deze verworven moet worden, verschilt per discipline. Een andere kwestie is of wetenschap gericht is op het verklaren of het begrijpen van fenomenen. Sommige wetenschappers zien als doel van (met name sociaalwetenschappelijk) onderzoek het verklaren van waarneembaar gedrag, terwijl het andere gaat om het doorgronden van menselijk handelen en denken in ruimere zin. Ook zijn de meningen verdeeld over de vraag of wetenschap een doel in zichzelf is of dat zij maatschappelijk relevant moet zijn. Daarnaast is discussie mogelijk over de vraag of de toegenomen interesse voor interdisciplinair onderzoek ook consequenties moet hebben voor de opzet en inrichting van het juridische onderwijs. Moet een jurist ook elementaire kennis bezitten van aanpalende disciplines als de sociologie, psychologie en filosofie?

\section{(iii) Methoden van rechtswetenschappelijk onderzoek}

In verschillende publicaties hebben onderzoekers van de 'Tilburgse school' het belang onderstreept van een goede methodologische verantwoording. Zij stellen drie minimumeisen aan een methodologisch verantwoorde verantwoording: ten eerste de aanwezigheid van een scherpomlijnde en verantwoorde probleemstelling; ten tweede een zorgvuldig bronnengebruik; en, ten derde, een consistente presentatie van onderzoeksresultaten (Van Gestel \& Vranken 2007). Hoewel deze eisen zeker van belang zijn, stellen we vast dat interessant en innovatief (rechts)wetenschappelijk onderzoek veel meer omvat dan dit ambachtelijk minimum. Welke eisen kunnen nog meer aan onderzoek worden gesteld en hoe moet hieraan in het juridisch onderwijs aandacht worden besteed? Hoe kan bijvoorbeeld originaliteit in het rechtswetenschappelijk onderzoek worden bevorderd (als dat al een vereiste is)? ${ }^{8}$

Met dit tijdschrift beogen wij het methodendebat in de rechtswetenschap een extra impuls te geven en de methodologische reflectie in het juridische onderzoek en onderwijs te bevorderen. Naast algemene theoretische beschouwingen is er ook ruimte voor concrete reflectie op onderzoek en onderwijs in de praktijk. Zo kunnen er interessante kruisbestuivingen ontstaan, niet alleen tussen theorie en praktijk maar ook tussen diverse wetenschappelijke benaderingen. Door verschillende invalshoeken te combineren - klassiek juridisch onderzoek naast interdisciplinair onderzoek, onderwijsmethoden in het hbo en op de universiteit, rechtswetenschap naast rechtspraktijk - wordt de rechtswetenschap verrijkt en blijven onderzoek en onderwijs in ontwikkeling.

\section{Literatuur}

\section{Barendrecht e.a. 2004}

M. Barendrecht e.a., 'Methoden van rechtswetenschap: komen we verder?', Nederlands Juristenblad 2004, p. 1419-1428. 


\section{Van der Aa 2010}

S. van der Aa, Stalking in the Netherlands. Nature and Prevalence of the Problem and the Effectiveness of Anti-Stalking Measures (diss. Tilburg), Apeldoorn: Maklu 2010.

\section{Buruma 2007}

Y. Buruma, 'Rechtswetenschap en praktijk', Nederlands Juristenblad 2007, p. 1043.

\section{De Geest 2004}

G. de Geest, 'Hoe maken we van de rechtswetenschap een volwaardige wetenschap?', Nederlands Juristenblad 2004, p. 58-66.

Van Gestel \& Vranken 2007

R. van Gestel \& J. Vranken, 'Rechtswetenschappelijke artikelen. Naar criteria voor methodologische verantwoording', Nederlands Juristenblad 2007, p. 1448-1461.

\section{Van Klink 2010}

B. van Klink, Rechtsvormen. Autonomie van recht en rechtswetenschap (oratie VU Amsterdam), Den Haag: Boom Juridische uitgevers 2010.

\section{Kloosterhuis 2009}

H. Kloosterhuis, Juridische methoden, Den Haag: Boom Juridische uitgevers 2009.

\section{Van Koppen 2011}

P. van Koppen, Overtuigend bewijs. Indammen van rechterlijke dwalingen, Uitgeverij

Nieuw Amsterdam: Amsterdam 2011.

\section{Mackor 2007}

A.R. Mackor, 'Tegen de methode', Nederlands Juristenblad 2007, p. 1462-1465.

\section{Mackor 2011}

A.R. Mackor, Grenzen aan professionele autonomie (oratie Groningen), 2011, beschikbaar op: http://www.rug.nl/staff/a.r.mackor/Mackor-oratie-2011-definitief.pdf.

\section{Marquard 2004}

O. Marquard, 'Apologie des Zufälligen', in: O. Marquard, Zukunft braucht Herkunft. Philosophische Essays, Stuttgart: Philipp Reklam 2003, p. 146-168.

\section{Van Schaaijk 2011}

G. van Schaaijk, Praktijkgericht juridisch onderzoek, Den Haag: Boom Juridische uitgevers 2011.

\section{Siems 2008}

M. Siems, 'Legal Originality', Oxford Journal of Legal Studies 2008, p. 147-154.

\section{Smith e.a. 2008}

C.E. Smith e.a., 'Criteria voor goed rechtswetenschappelijk onderzoek', Nederlands Juristenblad 2008, p. 685-690.

\section{Smits 2009}

J. Smits, Omstreden rechtswetenschap, Den Haag: Boom Juridische uitgevers 2009.

\section{Soeteman 2010}

A. Soeteman, 'Rechtswetenschappelijke zelfreflectie', Ars Aequi 2010, p. 182-186.

\section{Stolker 2003}

C. Stolker, 'Ja, geleerd zijn jullie wel!', Nederlands Juristenblad 2003, p. 766-778.

\section{Sumner e.a. 2010}

I. Curry-Sumner e.a., Onderzoeksmethoden/Research skills, Nijmegen: Ars Aequi 2010.

\section{Taekema 2010}

S. Taekema, Het probleem van pragmatisme, een vertrekpunt voor rechtstheorie en rechtsmethodologie (oratie Erasmus Universiteit Rotterdam), Den Haag: Boom Juridische uitgevers 2010. 


\section{Taekema \& Van Klink 2011}

S. Taekema \& B. van Klink, 'On the Border. Limits and Possibilities of Interdisciplinary Research', in: B. van Klink \& S. Taekema (red.), Law and Method. Interdisciplinary Research into Law, Tübingen: J.C.B. Mohr (Paul Siebeck) 2011.

\section{Tijssen 2009}

$\mathrm{H}$. Tijssen, De juridische dissertatie onder de loep, Den Haag: Boom Juridische uitgevers 2009.

\section{Wendt 2008}

I. Wendt, De methode der rechtswetenschap vanuit kritisch-rationeel perspectief, Zutphen: Paris 2008. 